\title{
PEMILIHAN METODE PENGURANGAN NOISE PADA CITRA ULTRASONOGRAFI OVARIUM
}

\author{
Eliyani $^{1)}$, Ahmad Riyadi Maulana ${ }^{2)}$ \\ ${ }^{1,2)}$ Jurusan Teknik Elektro- Universitas Muhammadiyah Gresik \\ eliyani.1306@gmail.com, ${ }^{2}$ hendra.umg@gmail.com \\ JL. Sumatra No 101, Gresik 61121, Jawa Timur
}

\begin{abstract}
ABSTRAK
Pengurangan noise merupakan upaya untuk memperbaiki kualitas citra yang akan memudahkan tahapan selanjutnya dalam pengolahan citra. Noise Reduction atau mengurangi noise untuk menghasilkan citra lebih baik sehingga informasi data citra tidak hilang dan citra dapat diintepretasikan oleh mata manusia. Penelitian ini menggunakan data gambar ultrasonografi ovarium untuk membantu menganalisa kondisi kesehatan ovarium perempuan. Gambar ultrasonografi ovarium biasanya terdapat noise, metode pengurangan noise yang akan digunakan pada penelitian ini adalah Median Filtering dan Adaptive Median Filtering. Hasil filtering dari 2 metode tersebut akan dibandingkan menggunakan Mean Square Error(MSE) dan Peak Signal To Noise Ratio(PNSR). Ukuran kernel untuk Median Filtering dan Adaptive Median Filtering dipilih sebagai 3x3, 5x5, dan 7x7. Penelitian ini menghasilkan metode filtering dengan kinerja terbaik yaitu Adaptive Median Filtering dengan ukuran window $5 \times 5$ yang ditunjukan dari nilai Mean Square Error dan Peak Signal To Noise Ratio .
\end{abstract}

Kata-kata kunci: Median Filtering, Adaptive Median Filtering, Mean Square Error, Peak Signal To Noise Ratio

\section{PENDAHULUAN}

Dokter dalam menganalisa kondisi kesehatan ovarium perempuan sering menggunakan hasil gambar ultrasonografi karena memberikan pemeriksaan cepat dan murah dibandingkan pemeriksaan di laboratorium. Gambar ultrasonografi ovarium sering digunakan dalam penerapan pengolahan citra dalam bidang kedokteran. Penerapan pengolahan citra menggunakan gambar ultrasonografi ovarium membutuhkan beberapa langkah yang harus dilakukan, misalnya mengurangi noise pada gambar ultrasonografi berupa speckle noise sehingga memudahkan saat ekstraksi ciri.

Gambar ultrasonografi ovarium sering digunakan di dunia medis karena memberikan pemeriksaan cepat dan murah dibandingkan pemeriksaan di laboratorium, tetapi kualitas gambar ultrasonografi ovarium kurang bagus karena terdapat banyak noise berupa speckle noise dalam gambar ultrasonografi [1].

\section{TINJAUAN PUSTAKA}

Pemrosesan awal citra terdiri dari 6 kategori yaitu filtering, edge operator, range transforms, surface orientation optical flow dan piramid [2]. Filtering atau penyaringan adalah suatu nama umum untuk teknik-teknik mengganti tingkat abu-abu citra untuk memperbaiki penampilan obyek. Perubahan ini sering bergantung pada karakteristik obyek. Suatu histogram tingkat abu-abu suatu citra atau gray-level histogram adalah suatu fungsi yang memberikan frekuensi kemunculan setiap tingkat abu-abu pada citra. 
Suatu perubahan citra yang sangat berguna seperti histogram equalization atau penyetaraan histogram [2]. Menurut [3], prinsip perbaikan kualitas citra (image enhancement) untuk menghasilkan citra yang lebih baik dari citra asli sehingga memudahkan dalam proses pengolahan citra lebih lanjut. Edge Operator mendeteksi dan mengukur ketidakberlanjutan yang sangat lokal pada intensitas atau gradiennya [2].

Hasil suatu operator tepi biasanya adalah magnitudo dan orientasi ketidakberlanjutan. Proses deteksi tepi menggunakan edge operator akan mendapatkan citra tepi. Tepi ditandai dengan adanya perubahan nilai intensitas yang mendadak atau kasar dalam jarak yang dekat. Deteksi tepi merupakan pendekatan yang paling umum untuk pendeteksian discontinuity nilai intensitas. Tujuan dilakukannya deteksi tepi adalah untuk meningkatkan penampakan garis batas suatu area atau objek di dalam citra. Ada beberapa metode yang terkenal dan banyak digunakan untuk pendeteksian tepi di dalam citra, yaitu operator Robert, operator Prewitt dan operator Sobel [2].

Metode Sobel paling banyak digunakan sebagai pelacak tepi karena kesederhananaan dan keampuhannya. Kelebihan dari metode ini adalah kemampuan untuk mengurangi noise sebelum melakukan perhitungan deteksi tepi. Masing-masing metode deteksi memiliki sub metode yang cukup banyak, tetapi metode deteksi citra yang baik adalah metode yang dapat mengeliminasi derau (noise) yang semaksimal mungkin [2].

Range transforms atau orientasi permukaan dapat dihitung jika sifat penyinaran dan pencerminan sumber pada permukaan diketahui. Perhitungan ini kadang disebut "shape from shading." Orientasi permukaan khususnya sederahana untuk dihitung ketika penyinaran sumber dapat dikendalikan [2].

Surface orientation atau perubahan rentang menggunakan geometri yang diketahui mengenai citra stereo untuk menyimpulkan jarak titik dari orang yang melihat. Perubahan ini menggunakan transformasi perspektif terbalik untuk menginterpretasikan bagaimana titik-titik pada ruang tidak dimensi terproyeksi pada pasangan stereo. Suatu korespondensi antara titik-titik pada dua citra stereo dari geometri yang diketahui menentukan rentang titik-titik tersebut. Rentang relatif juga bisa didapatkan dari korespondensi lokal tanpa mengetahui geometri pencitraan tepat [2].

Optical flow atau aliran optik, atau bidang kecepatan titik-titik citra, dapat dihitung dari variasi temporal dan spasial lokal dalam sekuensi citra tingkat abu-abu. Sistem biologis biasanya bergerak relatif terus menerus, dan gambar yang diproyeksikan pada retina pada dasarnya bervariasi terus menerus ketika mereka bergerak. Manusia merasakan gerakan terus menerus. Optical flow, memberikan setiap titik pada bidang visual "kecepatan retina" dua dimensi yang bergerak melintasi bidang visual. Perkiraan aliran sesaat dapat dihitung dari situasi input biasa dalam urutan gambar diskrit. Metode menggunakan aliran optik untuk menghitung gerakan pengamat, peta kedalaman relatif, normal permukaan di sekitarnya[2]. Piramida adalah suatu struktur umum untuk mewakili salinan-salinan citra pada beberapa resolusi. Suatu piramida adalah suatu "struktur utilitas" yang dapat secara dramatis memperbaiki kecepatan dan efektivitas banyak algoritma pengolahan awal dan segmentasi berikutnya [2].

Langkah preprocessing atau pra
pengolahan sangat penting supaya
mempermudah saat segmentasi [4], [5]. Speckle noise dalam gambar medis ultrasonografi bersifat multiplikatif dan sulit untuk menampilkan detail halus dari gambar [6], [7]. Sifat noise multiplikatif dimodelkan oleh Persamaan (1).

$$
\bar{k}[a, b]=k[a, b]+\eta[a, b] k[a, b]
$$

$\bar{k}[a, b]$ adalah versi digital dari noise $k[a, b]$ adalah gambar ultrasound ovarium asli dan $\eta[a, b]$ adalah fungsi noise. Penghapusan speckle noise dapat dilakukan dengan teknik denoising yang efisien [8].

Median filtering adalah salah satu teknik filter yang mengurutkan nilai intensitas sekelompok pixel, kemudian mengganti nilai pixel yang diproses dengan nilai median [4], [5], 
[9]. Gaussian lowpass filter berfungsi menekan derau yang tergambarkan dari distribusi citra, berfungsi juga untuk mereduksi hambatan atau noise tetapi memberi efek kabur pada citra. Menurut [10] metode menghilangkan noise yang digunakan [11] dengan gaussian low pass filter tidak mudah menemukan objek batas-batas sehingga hasil segmentasi masih kurang baik.

Biasanya, algoritma penghilangan noise yang sederhana memiliki kecepatan eksekusi yang lebih baik tetapi kurang efisien. Sebaliknya, algoritma penghilangan noise yang kompleks memiliki kinerja yang baik tetapi membutuhkan banyak waktu dalam komputasi, sehingga harus memilih wilayah yang diinginkan untuk menghemat waktu,yang membawa konsekuensi bahwa metode ini belum otomatis karena masih membutuhkan interaksi manusia.

\subsection{Median Filtering}

Median filtering adalah salah satu teknik image enhancement yang digunakan untuk menghilangkan noise dengan memanfaatkan fungsi median. Median adalah nilai tengah dari kumpulan data yang telah diurutkan.

Median filtering menggantikan nilai suatu piksel dengan nilai pada urutan tengah dari intensitas piksel tetangga dan dirinya (daerah pengamatan atau valuasi filter, sering disebut window uji filter atau dengan kata lain filter median, dalam proses ini setiap piksel asli diganti dengan nilai median piksel-piksel yang tercakup oleh suatu window yang berpusat pada piksel [12].

$$
M(x, y)=\operatorname{median}\{f(x-i, y-j),(i, j) \in w\}
$$

Persamaan (2) menerangkan bahwa $M(x, y)$ adalah citra yang dihasilkan dari citra $f(x, y), w$ sebagai window yang ditempatkan pad bidang citra dan $(i, j)$ elemen dari window tersebut.

Median filtering sangat efektif untuk menghilangkan noise serta tetap mempertahankan mutu gambar karena tidak bergantung pada nilai-nilai yang berbeda dengan nilai-nilai yang umum dalam lingkungannya.

\subsection{Adaptive Median Filtering}

Adaptive Median Filtering dirancang besarnya window (jendela/kernel) sekitarnya setiap piksel adalah variabel. Variasi ini tergantung pada median dari piksel dalam jendela sekarang atau saat ini. Jika nilai rata-rata adalah impuls, maka ukuran jendela akan diperluas. Jika tidak, proses lebih lanjut dilakukan pada citra dalam spesifikasi jendela saat ini.

Pengolahan citra diperlukan piksel pusat dari jendela (window) dievaluasi untuk memverifikasi apakah itu suatu impuls atau bukan. Jika itu adalah suatu impuls, maka nilai piksel baru pada gambar yang telah difilter akan menjadi nilai median dari piksel dalam jendela itu. Jika piksel pusat bukan suatu impuls, maka nilai dari pusat piksel akan dipertahankan dalam citra yang difilter.

Piksel yang dipertimbangkan sebagai sebuah impuls, nilai grayscale dalam piksel pada gambar yang difilter adalah sama dengan citra masukan. Adaptive median filtering memiliki tujuan ganda yaitu menghapus impuls noise pada gambar dan mengurangi distorsi pada gambar.

\section{METODOLOGI PENELITIAN}

Metodologi penelitian yang dilakukan ditunjukkan pada Gambar 1 yang menguraikan urutan langkah yang dilakukan untuk mendapatkan metode filtering terbaik. Akusisi citra pada penelitian ini digunakan untuk menghasilkan citra digital hasil USG ovarium pasien

Penelitian ini menerapkan 5 langkah seperti terlihat pada Gambar 1, citra ultrasonografi ovarium sudah dalam bentuk grayscale selanjutnya akan dilakukan proses cropping untuk memilih region of interest yang dibutuhkan, langkah selanjutnya mengetahui distribusi warna menggunakan histogram equalization. 
Pemilihan filtering untuk mendapatkan citra yang lebih baik dengan mengurangi noise pada citra tersebut menggunakan Median filtering dan Adaptive Median Filtering. Penilaian kinerja Median Filtering dan Adaptive Median Filtering dievaluasi menggunakan MSE dan PSNR.

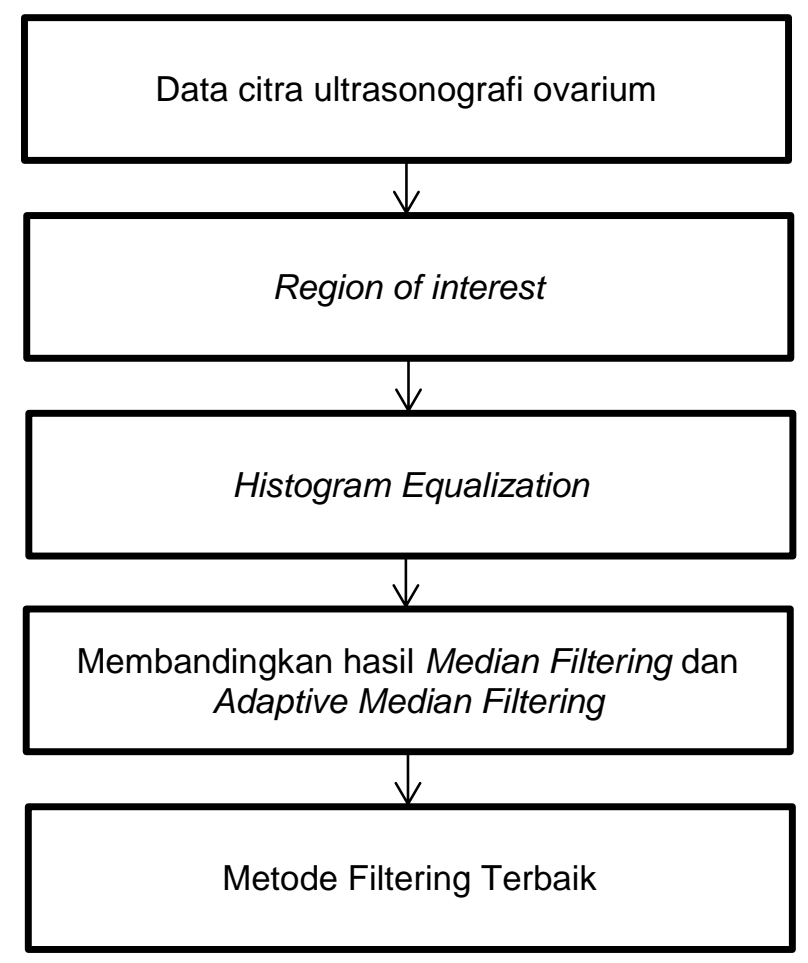

Gambar 1. Blok diagram pemilihan metode filtering terbaik.

Tahap awal pemrosesan citra atau preprosessing merupakan tahap paling mendasar yang perlu dilakukan sebelum citra diolah, berfungsi memperbaiki kualitas citra agar dapat menghasilkan ciri yang lebih baik pada tahap berikutnya. Penelitian ini akan menggunakan metode pre-prosessing atau pra pengolahan berupa histogram equalization serta akan mengurangi speckle noise.

Salah satu usaha untuk memperbaiki distribusi citra USG ovarium yang memiliki bentuk yang kurang jelas dengan menggunakan metode histogram equalization. Histogram adalah representasi grafis untuk distribusi warna dari citra digital atau menggambarkan penyebaran nilai-nilai intensitas pixel dari suatu citra atau bagian tertentu di dalam citra.
Histogram dapat diketahui frekuensi kemunculan dari intensitas pada citra, kecerahan, dan kontas dari sebuah gambar. Histogram dari suatu citra terlalu terang biasanya cenderung mengumpul di nilai grey level yang tinggi (ke arah nilai 255), sebaliknya histogram dari suatu citra yang terlalu gelap biasanya cenderung mengumpul di nilai grey level yang rendah (ke arah nilai 0 ).

Citra ultrasonografi ovarium terdapat speckle noise, maka untuk mengurangi speckle noise akan dilakukan median filtering dan adaptive median filtering. Hasil filtering akan dibandingkan menggunakan mean square error dan peak signal to noise ratio.

\section{HASIL PENELITIAN}

Teknik filtering yang diterapkan pada gambar ultrasonografi ovarium dengan metode median filtering. Contoh citra ultrasonografi ovarium ditunjukkan pada Gambar 2 yang akan digunakan untuk analisis mendapatkan metode filtering yang terbaik.

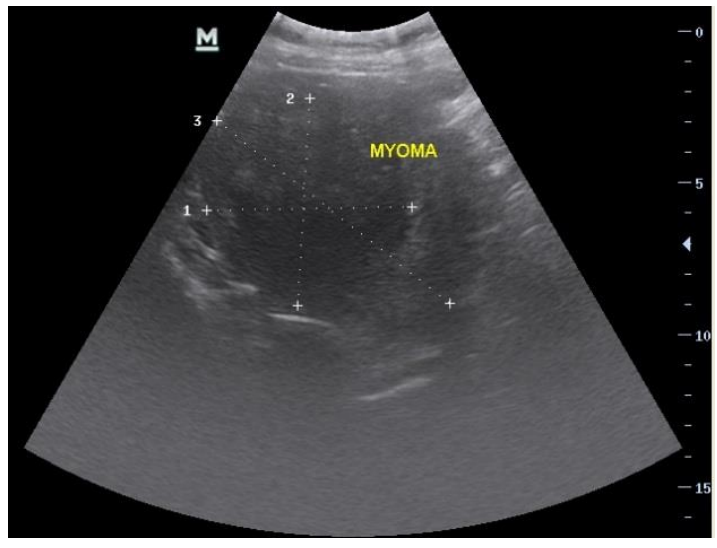

Gambar 2. Citra ultrasonografi ovarium.

Gambar 3 menampilkan hasil penelitian dengan langkah awal akusisi citra asli, selanjutnya melakukan pemilihan region of interest dengan cara cropping citra yang dibutuhkan, untuk mengetahui gambaran penyebaran nilai-nilai intensitas pixel dari citra ultrasonografi ovarium maka dilakukan proses histogram equalization, langkah selanjutnya melakukan filtering untuk mengurangi noise pada citra ultrasonografi ovarium menggunakan 
Median Filtering $(M F)$ dan Adaptive Median Filtering $(A M F)$.

Penilaian kinerja Median Filtering $(M F)$ dan Adaptive Median Filtering $(A M F)$ dievaluasi menggunakan MSE dan PSNR. Metode filtering yang terbaik adalah metode yang menghasilkan nilai MSE terkecil dan menghasilkan nilai terbesar PSNR.

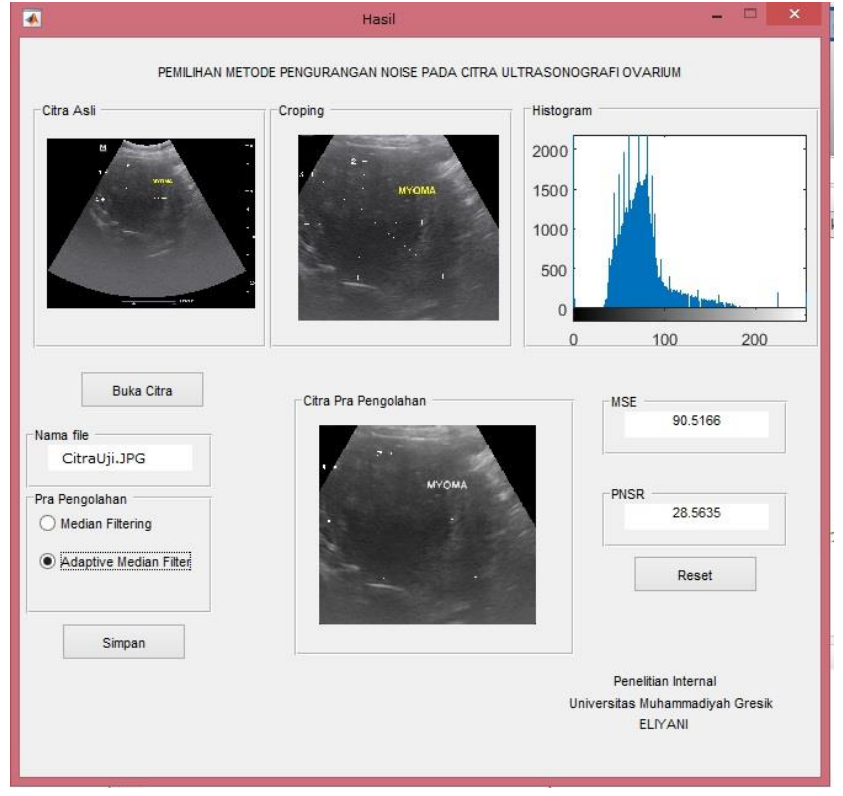

Gambar 3. Analisis citra ultrasonografi ovarium.

Kinerja metode filtering untuk Median Filtering dan Adaptive Median Filtering pada semua citra uji menggunakan ukuran kernel window size yaitu $3 \times 3,5 \times 5$, dan $7 \times 7$. Hasil nilai Mean Square Error(MSE) dan Peak Signal To Noise Ratio(PNSR) akan diamati untuk setiap kernel.

Tabel 1 terlihat nilai Mean Square Error(MSE) dan Peak Signal To Noise Ratio(PNSR) untuk setiap window size. Adaptive Median Filtering dengan window size 5x5 menghasilkan nilai PSNR sebesar 28.5635, Adaptive Median Filtering dengan window size 5x5 menghasilkan nilai MSE sebesar 90.5166.

Tabel 1. Kinerja metode filtering citra uji 1

Metode Window MSE

\begin{tabular}{ccrc}
\hline & size & & PSNR \\
\hline$M F$ & $3 \times 3$ & 208.2981 & 54.6721 \\
$M F$ & $5 \times 5$ & 208.2981 & 54.6721 \\
$M F$ & $7 \times 7$ & 208.2981 & 54.6721 \\
$A M F$ & $3 \times 3$ & 102.1416 & 32.2934 \\
$A M F$ & $5 \times 5$ & 90.5166 & 28.5635 \\
$A M F$ & $7 \times 7$ & 98.7834 & 30.3133 \\
\hline
\end{tabular}

Kinerja metode filtering pada Tabel 1 menunjukkan Adaptive Median Filtering dengan window size $5 \times 5$ menghasilkan nilai PSNR tertinggi dan nilai MSE terendah.

Tabel 2. Kinerja metode filtering citra uji 2

\begin{tabular}{cccc}
\hline \multicolumn{4}{c}{ Window } \\
Metode & size & MSE & PSNR \\
\hline$M F$ & $3 \times 3$ & 259.41791 & 14.3527 \\
$M F$ & $5 \times 5$ & 259.41791 & 14.3527 \\
$M F$ & $7 \times 7$ & 259.41791 & 14.3527 \\
$A M F$ & $3 \times 3$ & 153.8159 & 17.1258 \\
$A M F$ & $5 \times 5$ & 107.3651 & 18.9785 \\
$A M F$ & $7 \times 7$ & 122.4581 & 17.6436 \\
\hline
\end{tabular}

Diamati dari Tabel 2 terlihat nilai Mean Square Error(MSE) dan Peak Signal To Noise Ratio(PNSR) untuk setiap window size. Adaptive Median Filtering dengan window size 5x5 menghasilkan nilai PSNR sebesar 18.9785, Adaptive Median Filtering dengan window size 5x5 menghasilkan nilai MSE sebesar 107.3651.

Tabel 3. Kinerja metode filtering citra uji 3

\begin{tabular}{ccrc}
\hline \multicolumn{4}{c}{ Window } \\
Metode & size & \multicolumn{1}{c}{ MSE } & PSNR \\
\hline$M F$ & $3 \times 3$ & 329.3486 & 13.6421 \\
$M F$ & $5 \times 5$ & 329.3486 & 13.6421 \\
$M F$ & $7 \times 7$ & 329.3486 & 13.6421 \\
$A M F$ & $3 \times 3$ & 157.2541 & 24.3859 \\
$A M F$ & $5 \times 5$ & 88.4368 & 18.2761 \\
$A M F$ & $7 \times 7$ & 137.5174 & 22.5891 \\
\hline
\end{tabular}

Tabel 3 menunjukkan nilai Mean Square Error(MSE) dan Peak Signal To Noise Ratio(PNSR) untuk setiap window size. Adaptive Median Filtering dengan window size 5x5 menghasilkan nilai PSNR sebesar 18.2761, Adaptive Median Filtering dengan window size $5 \times 5$ menghasilkan nilai MSE sebesar 88.4368 . 
Hasil untuk semua citra uji diperoleh metode Adaptive Median filtering dengan window size $5 \times 5$ memiliki nilai Mean Square Error(MSE) terkecil dan menghasilkan nilai terbesar untuk Peak Signal To Noise Ratio(PNSR).

Tabel 4. Analisis kinerja Adaptive Median filtering dengan window size $5 \times 5$ untuk citra uji

\begin{tabular}{lrc}
\multicolumn{1}{c}{ Data } & \multicolumn{1}{c}{ MSE } & PSNR \\
\hline Citraujil & 90.5166 & 28.5635 \\
Citrauji2 & 107.3651 & 18.9785 \\
Citrauji3 & 88.4368 & 18.2761 \\
Citrauji4 & 132.6037 & 23.1422 \\
Citrauji5 & 115.2372 & 19.4482 \\
Citrauji6 & 99.1759 & 27.5498 \\
Citrauji7 & 142.4113 & 16.0853 \\
Citrauji8 & 129.38217 & 19.2334 \\
Citrauji9 & 151.9282 & 26.3937 \\
Citrauji10 & 109.1697 & 31.9004 \\
Citrauji11 & 118.6828 & 25.4675 \\
Citrauji12 & 97.2252 & 18.3536 \\
Citrauji13 & 125.5923 & 35.9785 \\
Citrauji14 & 106.1868 & 16.0173 \\
Citrauji15 & 98.3274 & 22.1136 \\
Citrauji16 & 125.7186 & 24.5873 \\
Citrauji17 & 102.2538 & 26.7701 \\
Citraujil8 & 98.9892 & 19.1874 \\
Citrauji19 & 163.1124 & 29.1125 \\
Citrauji20 & 111.3985 & 33.2197 \\
\hline
\end{tabular}

\section{KESIMPULAN}

Median filtering sangat efektif untuk menghilangkan noise serta tetap mempertahankan mutu gambar karena tidak bergantung pada nilai-nilai yang berbeda dengan nilai-nilai yang umum dalam lingkungannya. Adaptive median filtering dapat menangani operasi filter pada gambar rusak dengan impuls noise. Adaptive median filtering dengan ukuran window $5 \times 5$ dapat memperhalus noise, memberikan output citra jauh lebih baik dari standar median filtering. Hasil Adaptive median filtering diharapkan akan meningkatkan efisiensi proses segmentasi.

\section{Daftar Pustaka}

[1] Kushwaha, S., 2017. An Efficient Filtering Approach for Speckle Reduction in Ultrasound Images. , 10(3), hal.1355-1367.

[2] Ballard, D.H. dan Brown, C.M., 1982. Computer Vision, New Jersey (US): Prentice Hall.

[3] Gonzalez, R.C.. dan Woods, R.E., 2008. Digital image processing. Nueva Jersey, hal.976.

[4] Joel, T. dan Sivakumar, R., 2018. An extensive review on Despeckling of medical ultrasound images using various transformation techniques. Applied Acoustics, 138(June 2017), hal.18-27.

[5] Gupta, N., 2011. Comparative Study of Different Low Level Feature Extraction Techniques for Content based Image Retrieval., 1(1), hal.39-42.

[6] Yu, C., Zhang, C. dan Xie, L., 2012. A multiplicative Nakagami speckle reduction algorithm for ultrasound images. Multidimensional Systems and Signal Processing, 23(4), hal.499-513.

[7] Jabarullah, B.M., 2012. Survey on Noise Removal in Digital Images. IOSR Journal of Computer Engineering, 6(4), hal.45-51.

[8] Contreras Ortiz, S.H., Chiu, T. dan Fox, M.D., 2012. Ultrasound image enhancement: A review. Biomedical Signal Processing and Control, 7(5), hal.419-428.

[9] Chanu, P.R. dan Singh, K.M., 2018. Impulse Noise Removal from Medical Images by Two Stage Quaternion Vector Median Filter.

[10] Liu, J. dan Chen, H., 2017. Automatic detection of follicle in ultrasound images of cattle ovarian using MCL method. 2016 IEEE International Conference on Systems, Man, and Cybernetics, SMC 2016 Conference Proceedings, hal.1753-1757.

[11] Hiremath P. S. and Tegnoor J. R., 2010. Automatic Detection of Follicles in Ultrasound Images of Ovaries by Optimal Threshoding Method. International Journal of Computer Science and Information Technology, 3(2) 217-2.

[12] Jain, A.K., 1989. Fundamentals of Digital Image Processing, New Jersey, USA: Prentice-Hall International Editions. 